\title{
Nanocoating with plant-derived pectins activates osteoblast response in vitro
}

\author{
This article was published in the following Dove Press journal: \\ International Journal of Nanomedicine \\ 29 December 2016 \\ Number of times this article has been viewed
}

\author{
J Folkert \\ A Meresta' \\ T Gaber ${ }^{2}$ \\ K Miksch' \\ F Buttgereit ${ }^{2}$ \\ J Detert ${ }^{2}$ \\ N Pischon ${ }^{3, *}$ \\ K Gurzawska $3,4, *$ \\ 'Environmental Biotechnology \\ Department, Faculty of Power and \\ Environmental, Silesian University \\ of Technology, Gliwice, Poland; \\ 2Department of Rheumatology and \\ Clinical Immunology, ${ }^{3}$ Department \\ of Periodontology, Charité- \\ Universitätsmedizin, Berlin, Germany; \\ ${ }^{4}$ Department of Oral Surgery, The \\ School of Dentistry, University of \\ Birmingham, Birmingham, UK \\ *These authors contributed equally \\ to this work
}

\begin{abstract}
A new strategy to improve osseointegration of implants is to stimulate adhesion of bone cells, bone matrix formation, and mineralization at the implant surface by modifying surface coating on the nanoscale level. Plant-derived pectins have been proposed as potential candidates for surface nanocoating of orthopedic and dental titanium implants due to 1) their osteogenic stimulation of osteoblasts to mineralize and 2) their ability to control pectin structural changes. The aim of this study was to evaluate in vitro the impact of the nanoscale plant-derived pectin Rhamnogalacturonan-I (RG-I) from potato on the osteogenic response of murine osteoblasts. RG-I from potato pulps was isolated, structurally modified, or left unmodified. Tissue culture plates were either coated with modified RG-I or unmodified RG-I or - as a control - left uncoated. The effect of nanocoating on mice osteoblast-like cells MC3T3-E1 and primary murine osteoblast with regard to proliferation, osteogenic response in terms of mineralization, and gene expression of Runt-related transcription factor 2 (Runx2), alkaline phosphate (Alpl), osteocalcin (Bglap), $\alpha-1$ type I collagen (Collal), and receptor activator of NF- $\mathrm{KB}$ ligand (Rankl) were analyzed after 3, 7, 14, and 21 days, respectively. Nanocoating with pectin RG-Is increased proliferation and mineralization of MC3T3-E1 and primary osteoblast as compared to osteoblasts cultured without nanocoating. Moreover, osteogenic transcriptional response of osteoblasts was induced by nanocoating in terms of gene induction of Runx2, Alpl, Bglap, and Collal in a time-dependent manner - of note - to the highest extent under the PA-coating condition. In contrast, Rankl expression was initially reduced by nanocoating in MC3T3-E1 or remained unaltered in primary osteoblast as compared to the uncoated controls. Our results showed that nanocoating of implants with modified RG-I beneficially 1) supports osteogenesis, 2) has the capacity to improve osseointegration of implants, and is therefore 3 ) a potential candidate for nanocoating of bone implants.
\end{abstract}

Keywords: nanocoatings, osseointegration, osteoblasts, mineralization, Rhamnogalacturonan-I

\section{Introduction}

Nanotechnology in dentistry has expanded over the last years, especially in implant dentistry. Surface modification at the nanolevel has been reported in a number of studies to play a crucial role in osseointegration. ${ }^{1-12}$ A new strategy to improve osseointegration is biochemical stimulation by developing surface nanocoating, which is able to increase adhesion of bone cells, bone matrix formation, and mineralization at the implant surface.

Nanocoating with organic molecules and human-, animal-, and plant-derived polysaccharides demonstrated that complementary lectins to cell-surface carbohydrates have the ability to bind polysaccharide present at the surface and mediate cell response (Figure 1). ${ }^{4}$ Plant-derived pectins have been proposed as potential candidates for surface nanocoating of medical devices due to their effect on bone cells and the possibility of controlling their structure..$^{13-15}$ The effect on bone cells has been explained by a direct
Correspondence: K Gurzawska

Department of Oral Surgery,

The School of Dentistry, University

of Birmingham, St Chad's Queensway,

B4 6NN Birmingham, UK

Tel +44 I I I 4665496

Fax +44 I2I 4665493

Email k.a.gurzawska@bham.ac.uk (c) (1) (2) 2017 Folkert et al. This work is published and licensed by Dove Medical Press Limited. The full terms of this license are available at https://www.dovepress.com/terms.php
and incorporate the Creative Commons Atribution - Non Commercial (unported, v3.0) License (http://creativecommons.org/licenses/by-nc/3.0/). By accessing the work you BY NC and incorporate the Creative Commons Attribution - Non Commercial (unported, v3.0) License (http:///creativecommons.org/licenses/lby-nc/3.0/). By accessing the work you
hereby accept the Terms. Non-commercial uses of the work are permitted without any further permission from Dove Medical Press Limited, provided the work is properly attributed. For permission for commercial use of this work, please see paragraphs 4.2 and 5 of our Terms (https://www.dovepress.com/terms.php). 
Osteoblast cell-cell adhesion

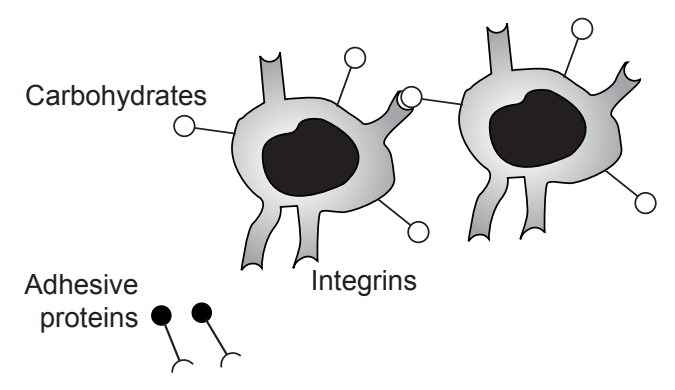

(4c)

Mineralization

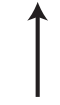

(4b)

Matrix

maturation

Direct Indirect adhesion

adhesion

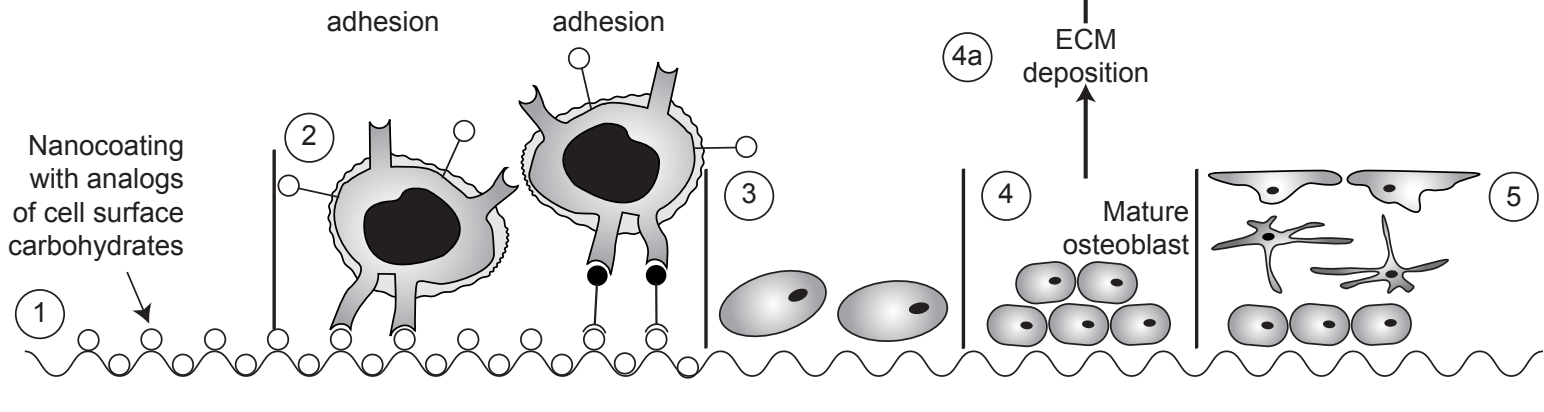

(4a)

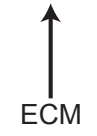

deposition

Titanium implant

Figure I Schematic representation of specific cell recognition and adhesion to titanium surface nanocoated with analogs of cell-surface carbohydrates (I), osteoblasts with integrins recognize and adhere directly or indirectly through adhesive proteins to the surface (2), followed by migration, proliferation (3), differentiation and maturation (4), and transformation into osteocytes and lining cells (5).

Note: Reproduced with permission from Gurzawska KA. Nanocoating of Implant Surfaces with Pectin Rhamnogalacturonan-ls, Review and In Vitro Studies [PhD thesis]. Copenhagen, Denmark: Faculty of Health and Medical Sciences, University of Copenhagen; 2013. ${ }^{31}$

Abbreviation: ECM, extracellular matrix.

adhesion of cells to pectins and indirectly through proteins binding to the pectins (Figure 1). ${ }^{4}$ The direct mechanism results in adhesion of bone cells directly to the surface. The indirect mechanism results in binding of a variety of proteins from the surrounding fluids to the surface, followed by selective binding to distinct receptors on the surface of invading cells. ${ }^{16,17}$ Binding to the receptors will elicit signals in the cells that result in enhanced adhesion, proliferation, and production of extracellular matrix (ECM). ${ }^{17}$ Osteoblast differentiation process is essential for development, maturation, and repair of the bone. ${ }^{18} \mathrm{~A}$ functional relationship between cell growth and the initiation and progression of events associated with cell differentiation is maintained and strictly regulated. ${ }^{19}$ The sequentially regulated expression of cell growth genes has defined three distinct phases of osteoblast development: 1) proliferation; 2) ECM synthesis, development, and maturation; and 3) ECM mineralization. ${ }^{19-21}$

As the osseointegration depends on osteoblast activity, it is important to investigate and understand the interaction between cell and the nanocoating at the surface. Pectin nanocoating has been reported in a number of studies to modulate the osteoblast response because of their chemical and physical properties. Pectin's chemical structure imitates the polysaccharides from the ECM of mammals, thus providing biospecific cell adhesion. ${ }^{22}$ It is possible to control the structure of pectin RG-I (Rhamnogalacturonan-I) by enzymatic modification. A variety of different pectin structures can be produced by changing the side chains (galactose and arabinose) or main chain (galacturonic acid and rhamnose) of the pectin molecule. Therefore, a screening of different RG-Is is important for identifying the regions of the RG-I molecule most important for bone cells and mineralized matrix formation. The hypothesis of our study is that galactose side chain will promote osteoblasts to produce mineralized matrix. The aim of this study was to evaluate in vitro the effect of nanocoating of polystyrene surfaces with unmodified and enzymatically modified (enrichment of galactose side chains) pectin RG-I from potato on osteoblasts with respect to their osteogenic response.

\section{Experimental}

\section{Isolation, modification, and analysis} of RG-I

\section{Isolation and modification of RG-I}

RG-I from potato pulps were isolated according to the previously published procedure. ${ }^{23}$ The enzymatic modification 
of potato RG-I was done using polygalacturonase-I (Novozymes, Copenhagen, Denmark) and polygalacturonaseIII (Novozymes) together with pectin methylesterase (Novozymes). The side chains of potato RG-I were treated with $\alpha$-L-arabinofuranosidase and endo-arabinanase to remove arabinan side chains and with $\beta$-galactosidase and endo- $\beta$-1,4-galactanase to remove galactan side chains. The monosaccharide composition and linkage analysis of unmodified potato (PU) and potato dearabinanated (PA) has been presented in our previous work. ${ }^{24}$

\section{Surface modification and characterization Surface nanocoating}

Adherent PU (unmodified) and PA (modified) RG-Is $(128 \mu \mathrm{g} / \mathrm{mL})$ were coated on the surface of 6-, 24-, and 96-well tissue polystyrene culture plates (TCPS) (Techno Plastic Products, Trasadingen, Switzerland). The reaction was carried out at room temperature overnight under sterile conditions on a shaker (IKA-Werke GmbH \& Co. KG, Staufen, Germany) at $100 \mathrm{rpm}$, and then the plates were extensively rinsed in sterile water and dried in a laminar flow hood before in vitro experiments.

\section{Surface nanocoating detection}

The recognition of PU and PA RG-Is nanocoating was performed using enzyme-linked immunosorbent assay (ELISA) before and after in vitro tests on the 24 -well plate $(n=2)$ in four wells selected randomly $(m=4)$ to detect the presence of the nanocoating. RG-Is (PU and PA)-coated wells and control wells without RG-Is were blocked for 15 minutes with $1 \mathrm{~mL} /$ well (24-well plate) 5\% (solution of fat-free milk powder in phosphate-buffered saline [PBS], pH 7.2) skimmed milk from Applichem (Darmstadt, Germany). Skimmed milk was removed from all the wells, and $1 \mathrm{~mL} /$ well of anti$(1 \rightarrow 4)-\beta$-galactan LM5 (Plant Probes, Leeds, UK) diluted $1: 10$ in 5\% skimmed milk was added. The 24 -well plate was placed on a shaker for 2 hours. All wells were washed with $5 \%$ skimmed milk three times (after adding the milk to the wells, the plate was placed on a shaker for 5 minutes). Secondary antibody, anti-rat IgG (whole molecule) from SigmaAldrich (Munich, Germany), was diluted 1:5,000 in 5\% of skimmed milk and $1 \mathrm{~mL}$ was added in each well. The plate was covered with aluminum foil and placed on the shaker for 2 hours. Subsequently, wells were washed three times with $1 \mathrm{M}$ PBS. Approximately $500 \mu \mathrm{L}$ of phosphate substrate was applied to each well, and the plate was placed on the shaker for 10 minutes. Colorimetric detection was performed with Microplate Reader 500 (Bio-Rad, Munich, Germany) at $450 \mathrm{~nm}$.

\section{In vitro studies}

The TCPS with PU and PA nanocoating were the test samples, and TCPS without the RG-Is were control samples. The in vitro assays, proliferation, mineralization, gene expression, and cell cycle analysis, were repeated six times each $(n=6)$. The osteogenic response was examined using mice osteoblast-like cells MC3T3-E1 and primary osteoblast isolated from calvariae of wild-type (WT) C57BL/6 mice. The primary osteoblasts were extracted from two samples of WT mice (WT1 and WT2), and all in vitro experiments were repeated twice.

\section{Cell culture}

MC3T3-E1 osteoblast-like cells were grown in cell culture medium consisting of minimum essential medium (Gibco, Darmstadt, Germany), 18\% fetal bovine serum (FBS; Biochrom, Berlin, Germany), antibiotic (100 mg/L streptomycin and $100 \mathrm{U} / \mathrm{mL}$ penicillin; Biochrom), and $10 \mathrm{~mL} / \mathrm{L}$ L-Glutamine (Biochrom) and incubated at $37^{\circ} \mathrm{C}$ with $5 \% \mathrm{CO}_{2}$ (Heraeus, Hanau, Germany). Primary cells (WT) were isolated from mice calvariae ( 3 days old) using digestion medium containing 0.2\% collagenase (Sigma-Aldrich), 0.25\%/0.5\% trypsin (Biochrom), and minimum essential medium (Gibco) and incubated at $37^{\circ} \mathrm{C}$ with $5 \% \mathrm{CO}_{2}$ (Heraeus) with cell culture medium consisting of minimum essential medium (Gibco), 10\% FBS (Biochrom), antibiotic (100 mg/L streptomycin and $100 \mathrm{U} / \mathrm{mL}$ penicillin) (Biochrom), and $10 \mathrm{~mL} / \mathrm{L}$ nonessential amino acids (Biochrom). For proliferation assays, $1 \times 10^{5}$ cells/mL were seeded on 96 -well TCPS plates and cultured for 12, 24, 48, and 72 hours. Cell culture for cell cycle analysis with fluorescence-activated cell sorting (FACS) was performed on $24-w e l l$ plates with $2 \times 10^{4}$ cells $/ \mathrm{mL}$ for 12 , 24, 48, and 72 hours.

For real-time polymerase chain reaction (PCR), $5 \times 10^{4}$ cells/mL were seeded on six-well TCPS plates and cultured for $3,7,14$, and 21 days. For mineralization, $2 \times 10^{4}$ cells $/ \mathrm{mL}$ were seeded on 24-well TCPS plates and cultured for 3, 7, 14, and 21 days. For mineralization assay, culture medium in all wells was replaced after 24 hours with mineralization medium additionally consisting of $50 \mu \mathrm{L} / \mathrm{mL}$ ascorbic acid (SigmaAldrich, Seelze, Germany) and $10 \mathrm{mM}$ glycerol 2-phosphate disodium salt hydrate (Sigma-Aldrich). The mineralization medium was changed every third day. The cells' morphology was observed daily by light microscopy (Leitz Labovert, Ernst Leitz Wetzlar GmbH, Wetzlar, Germany).

\section{Proliferation}

Cell proliferation was determined by bromodeoxyuridine (BrdU). The BrdU incorporated into newly synthesized 
DNA was quantified after 12, 24, 48, and 72 hours. Briefly, the proliferation assay was performed following the procedure described by the manufacturer (Roche Diagnostics GmbH, Mannheim, Germany). BrdU was added to the culture medium and incubated $\left(37^{\circ} \mathrm{C}, 5 \% \mathrm{CO}_{2}\right)$ for 2 hours. Afterward, the medium was removed and the cells were fixed in $70 \%$ ethanol for 30 minutes. Fixed cells were incubated with anti-BrdU antibody for 2 hours. The absorbance from each well was measured using the Microplate Reader 500 at $450 \mathrm{~nm}$. The wells without cells (ie, containing only culture medium) were used as a blank; wells with cells incubated with anti-BrdU antibody for unspecific binding were used as a background and were subtracted from all measurements.

\section{Cell cycle analysis}

Cell cycle analysis was based on DNA staining method using propidium iodide (PI, Sigma-Aldrich), which binds in proportion to the amount of DNA present in the cell. In brief, cells after 12, 24, 48, and 72 hours were washed twice with $1 \mathrm{~mL}$ PBS, trypsinized, resuspended in $150 \mu \mathrm{L}$ culture medium, and collected from three wells into one Eppendorf vial. Cells were harvested by centrifugation, 3,000 rpm for 10 minutes. The supernatant was discarded and the cells were washed with 500 $\mu \mathrm{L}$ PBS containing $2 \%$ FBS and harvested by centrifugation, at 3,000 rpm for 10 minutes. This procedure was repeated twice. Cells were fixed with $70 \%$ cold ethanol for 20 minutes at $4{ }^{\circ} \mathrm{C}$ and centrifuged at 3,000 rpm for 10 minutes. Afterward, cells were washed twice with $1 \mathrm{~mL}$ cold PBS containing $2 \%$ FBS and centrifuged at 3,000 rpm for 10 minutes. Approximately $300 \mu \mathrm{L}$ PBS containing $2 \%$ FBS and $1.5 \mu \mathrm{L}$ RNase were added. Subsequently, cells were stained with PI and resuspended before cell cycle analysis using FACSCalibur flow cytometer (Becton-Dickinson, Mansfield, MA, USA) and FlowJo software (version 10; Tree Star Inc., Ashland, OR, USA).

\section{Mineralization assay}

In the mineralization assay, cells were fixed in ice-cold $70 \%$ ethanol $(1 \mathrm{~mL} /$ well $)$ for 1 hour at $4^{\circ} \mathrm{C}$. The wells were washed with $1 \mathrm{~mL}$ distilled water, and the cell mineral matrix was stained with $500 \mu \mathrm{L}, 40 \mathrm{mM}$ Alizarin Red-S (AR-S; SigmaAldrich) at $\mathrm{pH} 4.2$ for 10 minutes at room temperature, with shaking rotation $100 \mathrm{rpm}$. The wells were washed three times with $1 \mathrm{~mL}$ distilled water and finally washed with $1 \mathrm{~mL}$ PBS with calcium and magnesium (PBS+, Biochrom AG) for 15 minutes at room temperature, with shaking rotation $100 \mathrm{rpm}$ to reduce nonspecific AR-S staining. Cell mineral matrix was destained in $500 \mu \mathrm{L} 10 \%$ cetylpyridynium chloride (CPC; Sigma-Aldrich) for 15 minutes at room temperature, with rotation $100 \mathrm{rpm}$. Standard dilution and AR-S extracts were added ( $200 \mu \mathrm{L} /$ well) into a 96-well ELISA plate and AR-S concentrations were determined at $562 \mathrm{~nm}$ using a Microplate Reader 500. Measurements were performed using $650 \mathrm{~nm}$ as reference. Additionally, standards were applied, $1.0 \mathrm{mM}$ AR-S and 10\% CPC (Sigma-Aldrich), to calculate the content of calcium in each well using analytical curve.

\section{Gene expression, real-time PCR}

RNA isolation using the RNeasy mini kit (Qiagen, Hilden, Germany) and the reverse-transcription PCR using onestep high-capacity cDNA reverse-transcription kit (Applied Biosystem, Foster City, CA, USA) were performed as previously described. ${ }^{25}$ A comparative threshold cycle $\left(C_{t}\right)$ method was selected for gene expression analysis performed with CFX96 Real-Time PCR Detection System (Bio-Rad). SsoAdvanced ${ }^{\text {TM }}$ Universal SYBR Green Supermix (Bio-Rad) was used for expression of target genes: Runt-related transcription factor 2 (Runx2), alkaline phosphatase ( $A l p l)$, osteocalcin (Bglap), $\alpha-1$ type I collagen (Collal), receptor activator of NF-кB Ligand (Rankl), and beta actin (Actb) as endogenous control gene. Manually prepared cDNA of 2 and $8 \mu \mathrm{L}$ reaction mix were pipetted to each well of 96-well plate (Bio-Rad), according to manufacturer's instructions. Results were shown using the comparative $C_{\mathrm{t}}$ method $\left(\Delta \Delta C_{\mathrm{t}}\right)$. As a $C_{\mathrm{t} \text { reference }}$ beta $\operatorname{actin}(A c t b)$ has been used for each of sample.

\section{Statistical analyses}

Descriptive statistics were used and mean values were calculated. Results of surface analysis as well as results from the in vitro experiments were analyzed using one-way analysis of variance (ANOVA) tests and Bonferroni corrections for multiple comparisons to control using SPSS version 11.5 software (SPSS Inc., Chicago, IL, USA). A significance level (a $P$-value) of $5 \%$ was used throughout.

\section{Results}

\section{Detection of RG-I surface nanocoating}

The RG-I PU and PA were detected before in vitro tests and after 21 days of cell culture. The results showed presence of the nanocoating with PU and PA with colorimetric staining, while on the control surface without the nanocoating, the absorbance was close to zero (Figure 2). After 21 days of cell culture, the results still showed presence of PU and PA, but with lower amount than before the in vitro test.

\section{In vitro studies}

The in vitro results will be presented only for one sample of WT cells as a significant difference was not found between WT1 and WT2. 


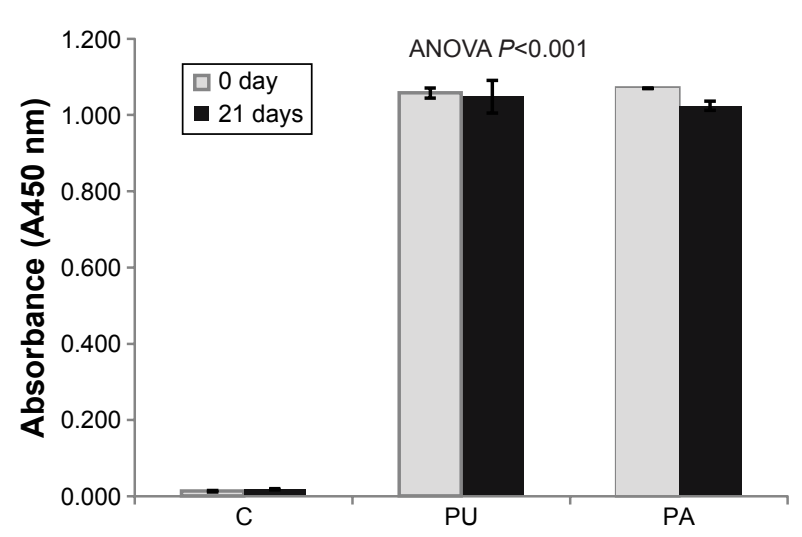

Figure 2 Presence of the nanocoating with PU and PA with immunofluorescence staining using anti-( $I \rightarrow 4)-\beta$-galactan LM5 and Anti-rat IgG (whole molecule)-alkaline phosphatase antibody.

Note: The results represent absorbance values measured at $450 \mathrm{~nm}$ before in vitro test and after $2 \mathrm{I}$ days of WT cell culture.

Abbreviations: ANOVA, analysis of variance; IgG, immunoglobulin G; PA, potato dearabinanated; PU, potato unmodified; WT, wild-type mice primary osteoblast from calvariae; LM, lyphophilized rat monoclonal protein-G; C, control tissue culture polystyrene surface.

\section{Cell morphology}

The WT and MC3T3-E1 cell morphology investigated with light microscopy showed osteoblastic cells with spreadout morphology when cultured on both noncoated and RG-Is-nanocoated surfaces after 24, 48, and 72 hours. No difference in cell morphology was observed between the control TCPS-, PA-, and PU-coated surfaces.

\section{Proliferation}

RG-I coating did not influence the proliferation of MC3T3-E1 and primary osteoblasts as compared to the uncoated controls after 12, 24, 48, and 72 hours (Figure 3). The proliferation of WT and MC3T3-E1 cells increased over time from 12 to 72 hours, reaching the highest value at 72 hours. The proliferation of WT cells at PA was higher than at PU, and proliferation at PU was higher than at the control TCPS surface in each period of time, 12, 24, 48, and 72 hours. The difference in proliferation rate over time was observed between the cell line MC3T3-E1 and WT cells. The highest amount of proliferating cells was detected in the MC3T3-E1 culture and the lowest in WT primary cell culture.

\section{Cell cycle analysis (FACS)}

Cell cycle analysis using flow cytometry did not show significant differences in the percentages of MC3T3-E1 and WT cells in $\mathrm{G}_{1}, \mathrm{~S} / \mathrm{M}$, and $\mathrm{G}_{2}$ phases on PU and PA compared to TCPS control after 72 hours. A significant increase in the cell frequencies (\%) was found in $\mathrm{G}_{1}$ phase in MC3T3-E1 cells cultured at PU-coated surface compared to PA-coated surfaces ( $P \leq 0.05$; Figure 4).

\section{Mineralization}

The mineralization assay showed no significant increase in matrix deposition for cells cultured on surfaces coated with PU and PA compared to control TCPS for MC3T3-E1 and WT after 3, 7, 14, and 21 days. The mineralization results, for both WT and MC3T3-E1, showed increase of mineralized matrix over time, and the highest amount was observed after 21 days. The amount of mineralized matrix was higher in MC3T3-E1 compared to WT cells (Figure 5).

\section{Gene expression}

The real-time PCR results of gene expression measured at different end points $(3,7,14$, and 21 days) are shown

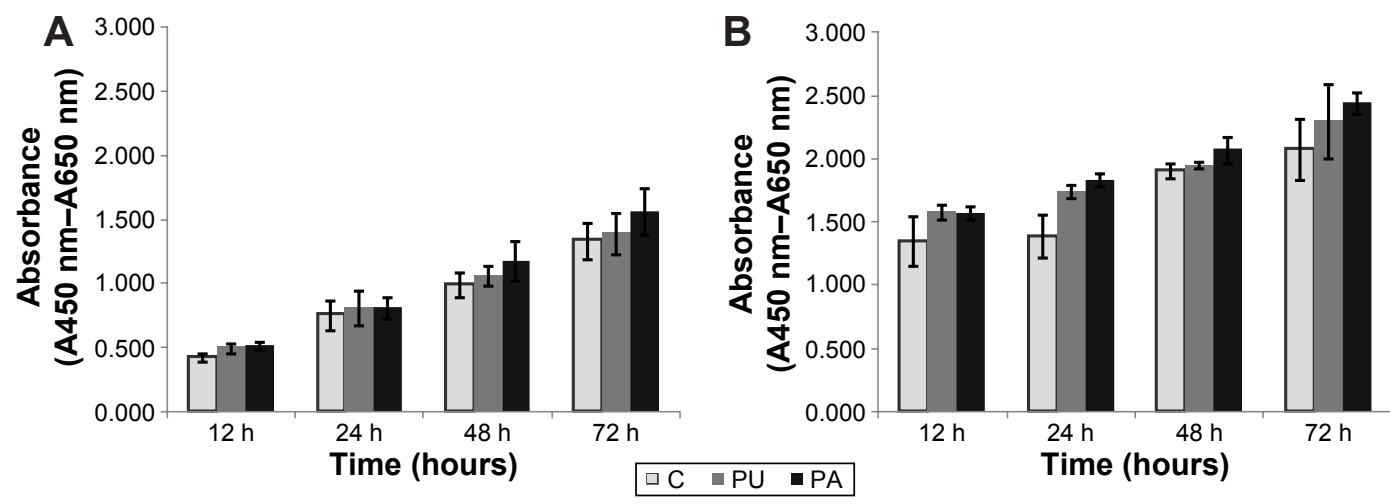

Figure 3 Proliferation activity of WT cells $(\mathbf{A})$ and osteoblastic cells MC3T3-EI (B) measured by the colorimetric method using BrdU after I2, 24, 48, and 72 hours (mean \pm SEM, $n=6$ ).

Notes: The results represent absorbance values measured at $450 \mathrm{~nm}$ against the background control wells using $650 \mathrm{~nm}$ as a reference. ANOVA tests and Bonferroni corrections were performed for multiple comparisons. A significance level of 0.05 was used throughout the study. There was no significant difference between tested (PU and PA) and $C$ samples.

Abbreviations: ANOVA, analysis of variance; BrdU, bromodeoxyuridine; C, control TCPS; h, hour; PA, potato dearabinanated; PU, potato unmodified; RG-I, rhamnogalacturonan-I; SEM, standard error of the mean; TCPS, tissue culture polystyrene surface; WT, wild-type mice primary osteoblast from calvariae. 
A
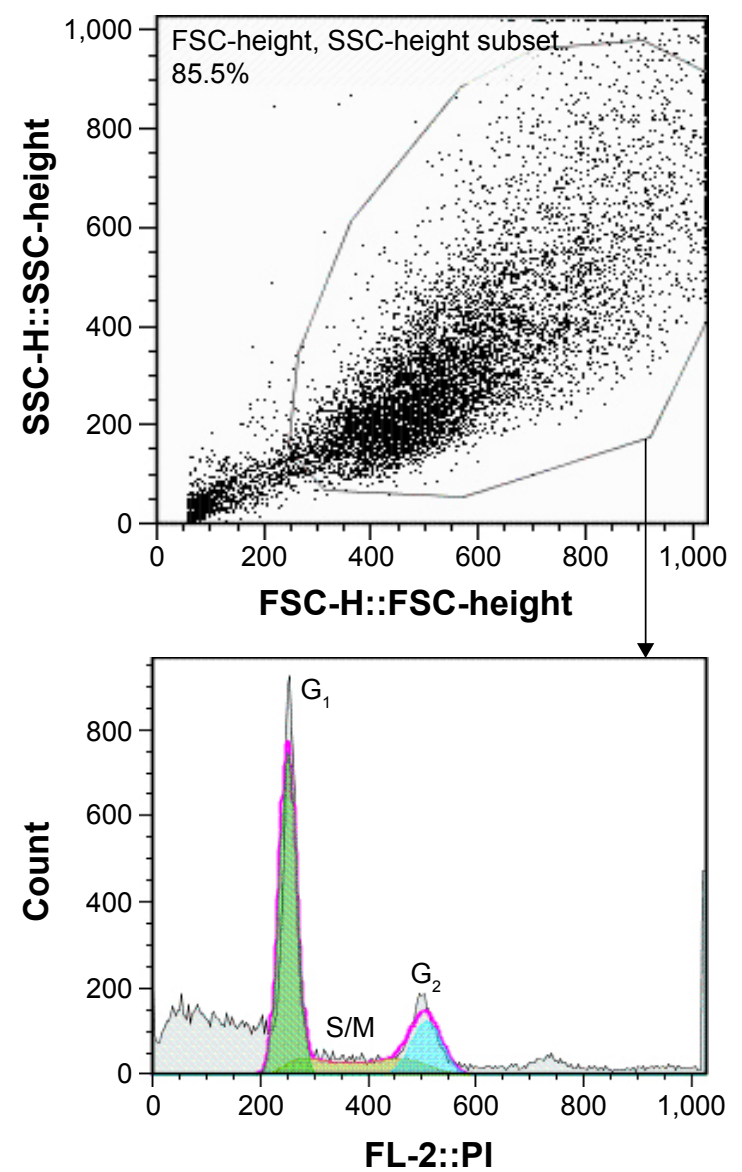

B

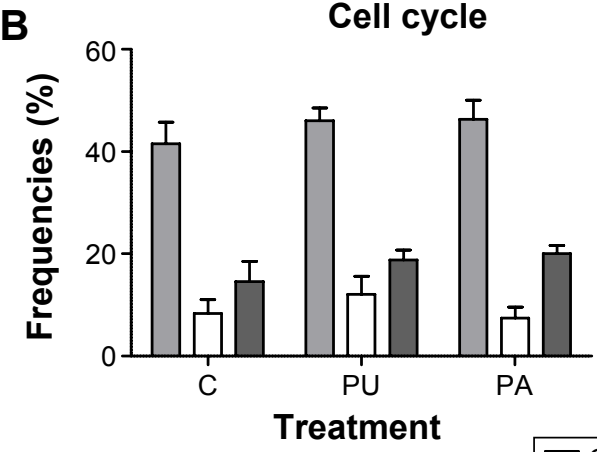

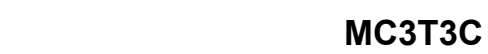
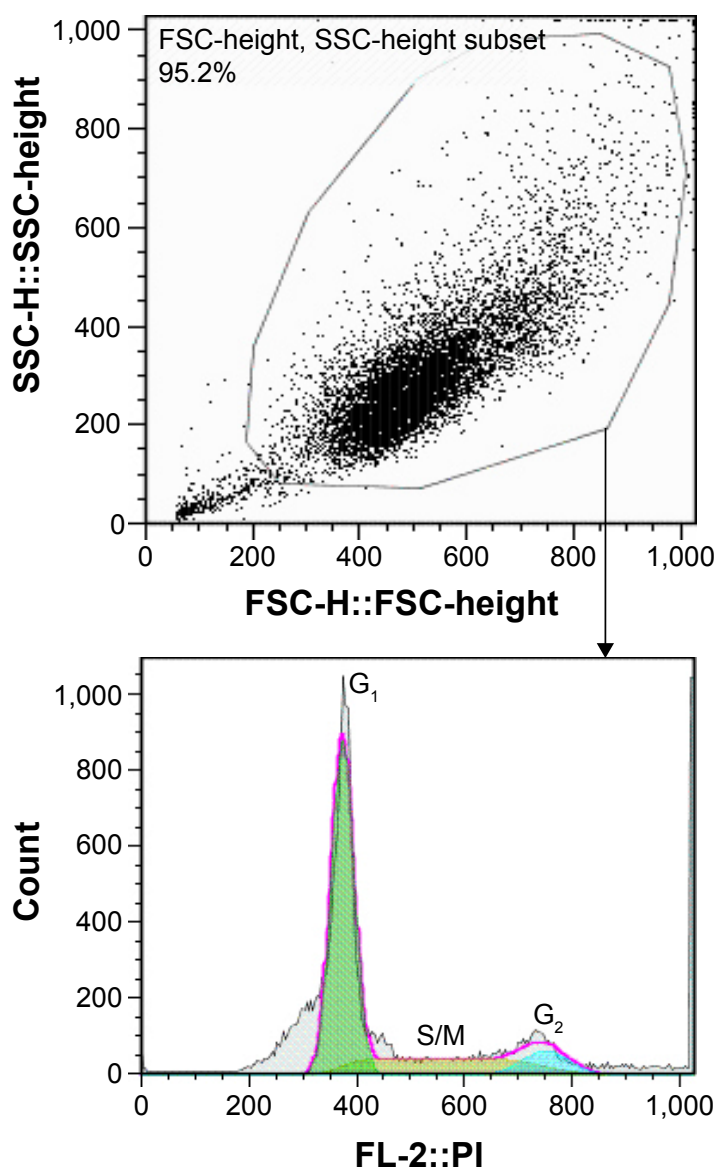

FL-2::PI

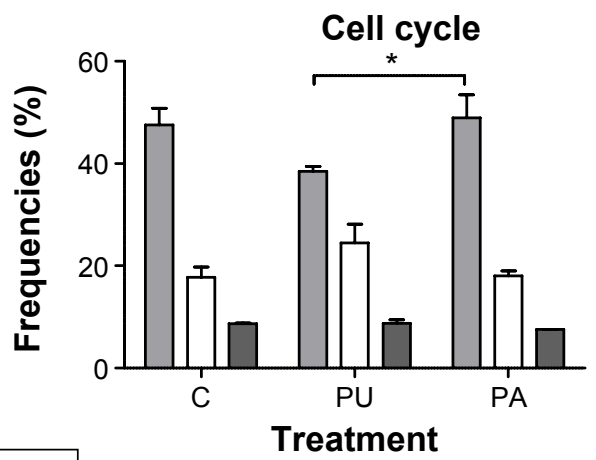

Figure 4 Cell cycle analysis of MC3T3-EI and WT cells cultured on PU, PA, and uncoated TCPS (control) after 72 hours.

Notes: (A) Representative diagrams of osteoblastic MC3T3-EI and WT cells. (B) Frequencies (\%) of MC3T3-EI and WT cells in $G_{1}, S / M$, and $G_{2}$ phases (mean \pm SEM, $n=6$ ). ANOVA tests and Bonferroni corrections were performed for multiple comparisons. A significance level of 0.05 was used throughout the study. There was no significant difference between tested (PU and PA) and $C$ samples. Significant difference between PU and PA: $* P<0.05$.

Abbreviations: ANOVA, analysis of variance; C, control TCPS; PU, potato unmodified RG-I; PA, potato dearabinanated RG-I; RG-I, rhamnogalacturonan-I; SEM, standard error of the mean; TCPS, tissue culture polystyrene surface; WT, wild-type mice primary osteoblast from calvariae; SSC, side scatter; FSC, forward scatter; FL, fluorescence; $\mathrm{PI}$, propidium iodide.

in Figure 6. Gene expression of Runx2, Colla1, Alpl, Bglap, and Rankl was measured as they increased over time, from 3 to 21 days.

Runx2 expression in MC3T3-E1 and WT cultured at PU- and PA-coated surfaces was significantly different compared to control TCPS at different time points, as illustrated in Figure 6. In MC3T3-E1 and WT cells cultured on surface coated with PA, Runx2 expression after 3, 7, 14 , and 21 days was significantly upregulated compared to control TCPS (WT: $P \leq 0.05$ after 3 days, $P \leq 0.001$ after 7, 14, and 21 days; MC3T3-E1: $P \leq 0.05$ after 3 days, $P \leq 0.01$ after 7,14 , and 21 days). On the surface coated with 

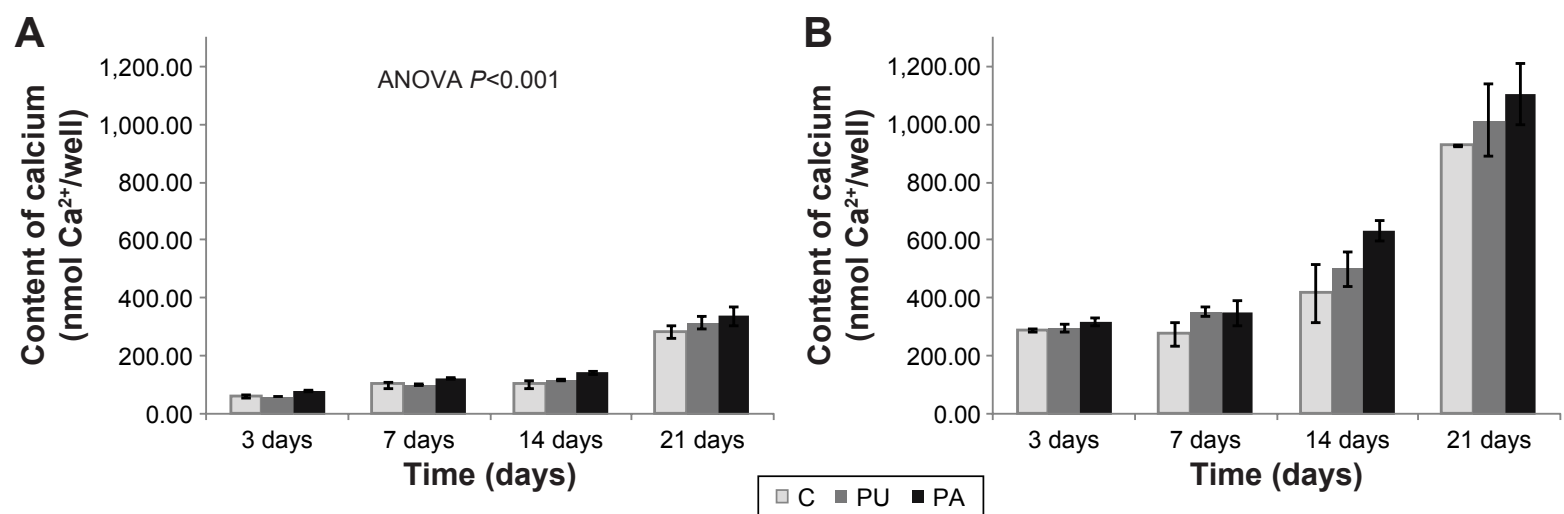

Figure 5 Relative mineralization of ECM, measured by an AR-S staining assay after 7 days (mean $\pm S E M, n=6$ ).

Notes: Results in nmol Ca ${ }^{2+}$ AR-S correspond to amount of AR-S bound to $2 \mathrm{~mol} \mathrm{Ca}{ }^{2+} / \mathrm{mol}$ of dye in solution. ANOVA tests and Bonferroni corrections were performed for multiple comparisons. A significance level of 0.05 was used throughout the study. There was no significant difference between tested (PU and PA) and C samples in WT cells (A) and MC3T3-EI osteoblastic cells (B) cultured on plates coated with PU, PA, and C.

Abbreviations: ANOVA, analysis of variance; AR-S, Alizarin Red-S; C, control TCPS; ECM, extracellular matrix; PU, potato unmodified RG-I; PA, potato dearabinanated RG-I; RG-I, rhamnogalacturonan-I; SEM, standard error of the mean; TCPS, tissue culture polystyrene surface; WT, wild-type mice primary osteoblast from calvariae.

A
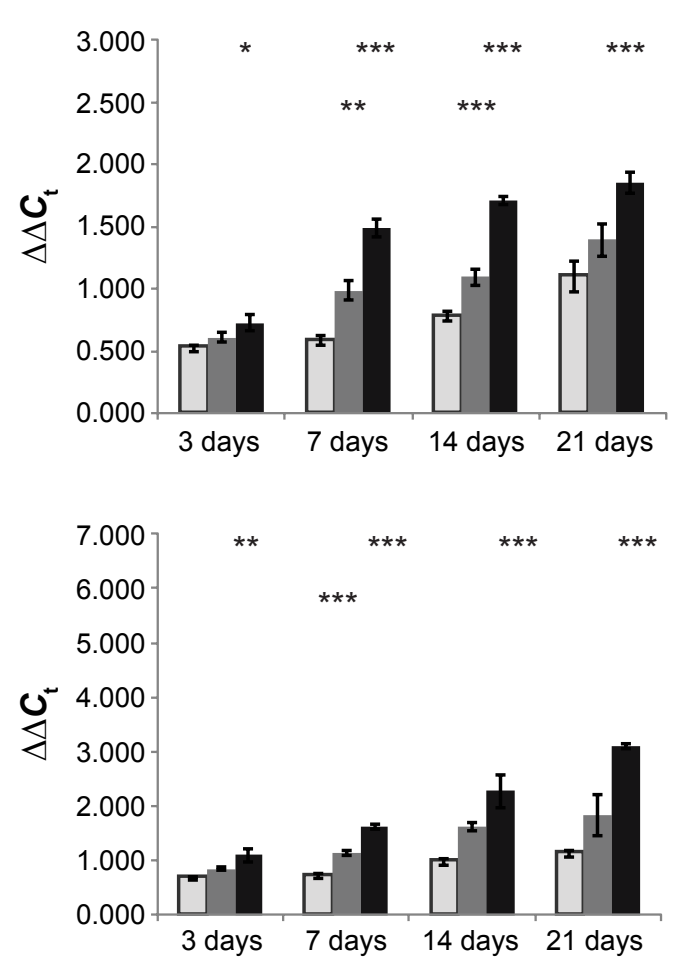

B

Runx2

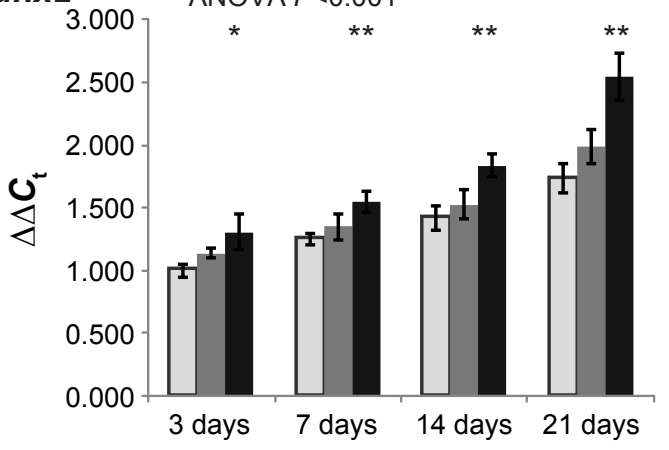

Col1a1

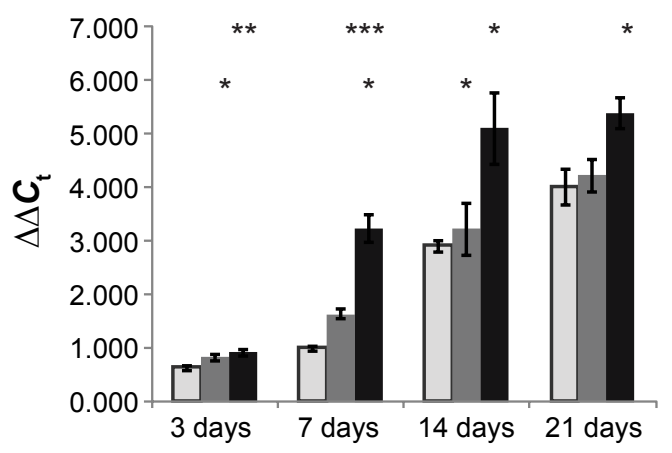

Alpl

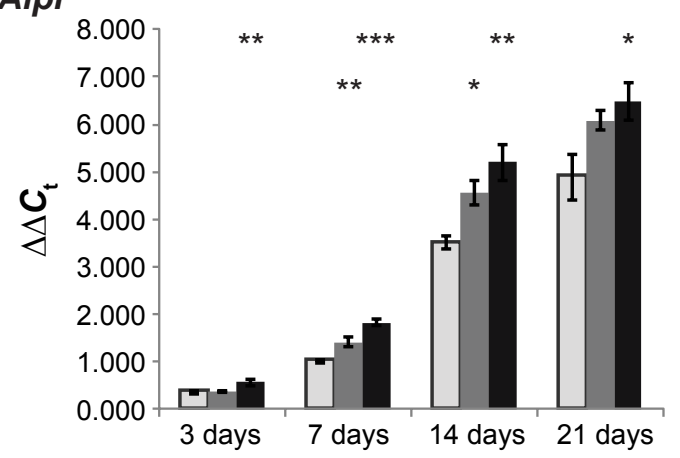

Figure 6 (Continued) 


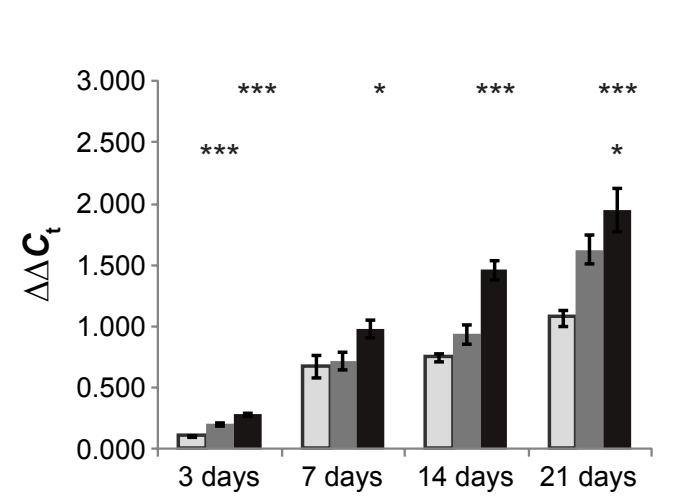

Bglap

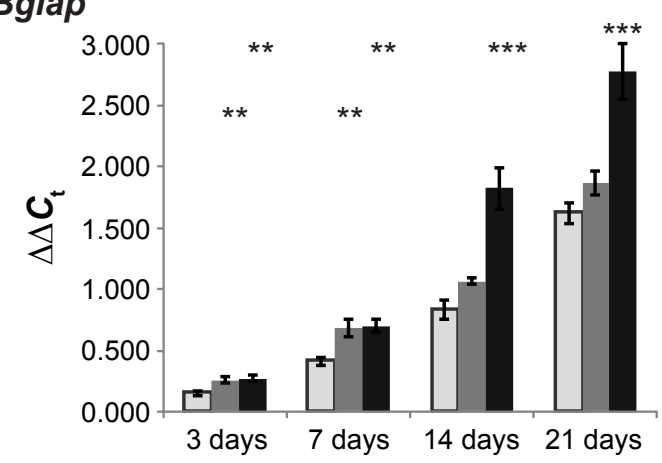

Rankl
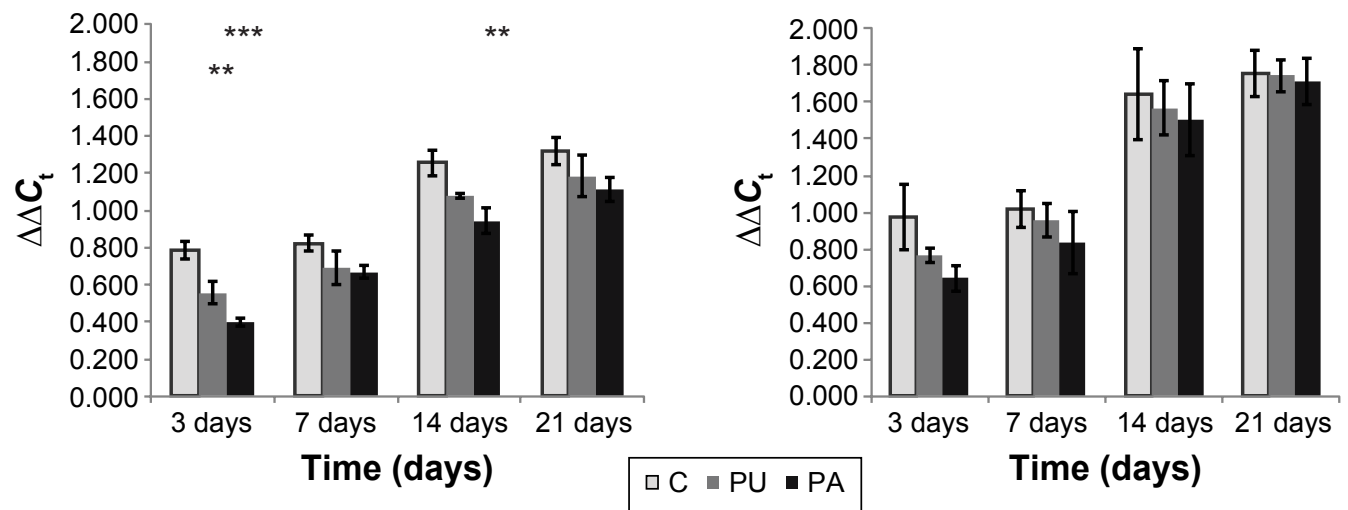

Figure 6 Real-time PCR measurements of the gene expression of Runx2, Collal, Alpl, Bglap, and Rankl in WT cells (A) and MC3T3-EI osteoblastic cells (B) cultured on plates coated with PU, PA, and C.

Notes: Values on the $y$-axis represent amplification efficiency $\left(\Delta \Delta C_{t}\right)$. Results are mean \pm SEM of six independent. ANOVA tests and Bonferroni corrections were performed for multiple comparisons. A significance level of 0.05 was used throughout the study. Significant difference between $C$ and tested samples $(P U$ and $P A): * P<0.05 ; * * P<0.0$; $* * * P<0.001$.

Abbreviations: ANOVA, analysis of variance; Alpl, alkaline phosphate; Bglap, osteocalcin; Collal, collagen type-I; C, control TCPS; PCR, polymerase chain reaction; PA, potato dearabinanated RG-I; PU, potato unmodified RG-I; RG-I, rhamnogalacturonan-l; Rankl, receptor activator for nuclear factor; Runx2, osteoblast transcription factor (runt-related gene 2); SEM, standard error of the mean; TCPS, tissue culture polystyrene surface; WT, wild-type mice primary osteoblast from calvariae.

PU, Runx2 expression was significantly upregulated after 7 and 14 days in WT cell culture compared to control TCPS ( $P \leq 0.05$ after 3 days, $P \leq 0.001$ after 14 days). The expression of Runx2 was the highest in MC3T3-E1 and WT cell cultures at the surface coated with PA and was the lowest on the control TCPS.

In general, Colla1, Alpl, and Bglap expressions at different time points $(3,7,14$, and 21 days) were the highest at PA-coated surface in MC3T3-E1 and WT cell cultures. Expression of Colla1, Alpl, and Bglap in MC3T3-E1 and WT cells cultured at PU was lower than those cultured at PA, but higher than at control TCPS surface.

The Collal in WT cell culture was found to be expressed significantly higher ( $P \leq 0.01$ after 3 days, $P \leq 0.001$ after 7, 14 and 21 days) at PA compared to control TCPS. The Collal in MC3T3-E1 cell culture was found to be expressed significantly higher ( $P \leq 0.01$ after 3 days, $P \leq 0.001$ after 7 days, $P \leq 0.05$ after 14 and 21 days) at PA compared to control TCPS. For PU-coated surface, the Collal expression was significantly higher $(P \leq 0.001)$ after 7 days in the WT cell culture. In MC3T3-E1, the gene expression was significantly higher after 3,7 , and 14 days $(P \leq 0.05)$.

The Alpl in WT cell culture was significantly higher $(P \leq 0.001)$ at PA compared to control TCPS at each time end point. Alpl expression in MC3T3-E1 cell culture was significantly higher ( $P \leq 0.01$ after 3 and 14 days, $P \leq 0.001$ after 7 days, $P \leq 0.05$ after 21 days) at PA compared to control TCPS. For PU-coated surface, the Alpl expression in WT cell culture was significantly higher ( $P \leq 0.05$ after 3 days, $P \leq 0.001$ after 7 and 21 days, and $P \leq 0.01$ after 14 days) compared to control TCPS. In MC3T3-E1 cell culture at PU-coated surface, the Alpl expression was significantly higher ( $P \leq 0.01$ after 7 days and $P \leq 0.05$ after 14 days) compared to control TCPS.

Bglap expression in WT cell culture at PA was significantly higher $(P \leq 0.001$ after 3,14 , and 21 days and $P \leq 0.05$ after 7 days) compared to control TCPS. In MC3T3-E1, Bglap expression at PA-coated surface was significantly 
higher ( $P \leq 0.01$ after 3 and 7 days and $P \leq 0.001$ after 14 and 21 days). The expression of Bglap in WT cell culture at PUcoated surface was significantly higher after $3(P \leq 0.001)$ and 21 days $(P \leq 0.05)$ compared to control TCPS. The expression of Bglap in MC3T3-E1 cell culture at PU-coated surface was significantly higher after 3 and 7 days $(P \leq 0.01)$ compared to control TCPS.

Rankl expression in WT cell culture was found to be significantly lower $(P \leq 0.001$ after 3 days and $P \leq 0.01$ after 14 days) at PA compared to control TCPS. The expression of Rankl in MC3T3-E1 cells was not found to be significantly lower at PA compared to control TCPS. For PU-coated surface, the Rankl expression was significant lower $(P \leq 0.01)$ after 3 days in WT cell culture. In MC3T3-E1, no significant difference in gene expression was observed between PU and control TCPS.

\section{Discussion}

The aim of this study was to evaluate in vitro the effect of nanocoating of polystyrene surfaces with pectin RG-I from potato on osteoblasts with respect to their osteogenic response. To test the hypothesis of our studies that galactose side chain of RG-I will promote osteoblasts to produce mineralized matrix, analysis of enzymatically modified RG-I was included.

Our results demonstrate that osteoblasts are sensitive to surface modification of RG-Is coating. The cells cultured on surfaces coated with RG-Is containing higher amount of galactose produced higher level of mineralized matrix compared with controls. Furthermore, increased level of gene expression of Runx2, Collal, Alpl, and Bglap and decreased level of Rankl were detected in cells cultured on surfaces coated with RG-Is, PU, and PA.

In general, the difference between PU and modified RG-I, PA was reflected by the sugar composition. ${ }^{24}$ Chemical components of the RG-I structure influenced osteoblast activity, which is in agreement with other studies. ${ }^{13-15,22,25,26}$ Our findings support results from earlier studies, indicating that surfaces coated with RG-I containing short arabinan side chains and high amount of galactose enhance fibroblast and osteoblast cells spreading and growth, in contrast to the RG-I with high amount of arabinose, which led to aggregation and decreased proliferation..$^{15}$ In this study, we proved that high content of galactose, present in PA and PU, promoted osteoblasts to produce mineralized matrix. Our finding is also in agreement with previous studies performed at polystyrene and titanium surfaces showing that RG-Is with higher amount of galactose side chains activated human osteoblast-like cells,
SaOS-2, to mineralize..$^{24,25,27}$ In this study, osteoblast-like cells, MC3T3-E1, and primary WT osteoblasts from mice were used to confirm the hypothesis that galactose stimulates the mineralization process at different end points.

The highest proliferation (BrdU) of MC3T3-E1 and WT cells at different end points was reported on PA-coated surface with high content of galactose. However, the results of FACS analysis showed that PU and PA did not significantly influence MC3T3-E1 and WT cell cycle progression compared to cells cultured on TCPS control. Proliferation (BrdU) of MC3T3-E1 and WT cells at different end points was reported to be the highest on PA with high content of galactose. These results are the first to show the RG-Is effect on osteoblast proliferation measured with BrdU assay and cell cycle analysis (FACS analysis). Kokkonen et a ${ }^{14}$ investigated the effect of RG-Is from apple on MC3T3-E1 cell number and morphology. The findings showed an increase in the number of cells and more spread morphology at surfaces coated with the RG-Is with shorter side chains of arabinose compared to the surface coated with RG-I with longer side chains of arabinose. ${ }^{26}$

The direct contact between RG-I side chains and the cells might affect cell behavior. ${ }^{25}$ Adhesion of the cells promotes proliferation and further differentiation. ${ }^{8}{ }^{814}$ Our findings indicate that RG-Is coating might promote adhesion of the cells, resulting in an increase in proliferation and differentiation. Adhesion of the cells to the surface is the first step in osseointegration, which initiates cell growth and differentiation. ${ }^{19}$ A mutual relationship between cell growth and progression of events associated with osteoblast differentiation and matrix formation and maturation can be observed by measuring gene expression levels in real-time PCR. The gene expression has been supplemented in our study with colorimetric assay (AR-S) to analyze mineralization process by measuring mineralized matrix formation. Gene expression and mineralization were examined at different time points $(3,7,14$, and 21 days) to identify behavior of osteoblasts during the whole osteoblast lineage. The selection of time points was based on our own experience and other studies. ${ }^{28}$ The results of mineralization showed an increase in matrix deposition for cells cultured on surfaces coated with PA and PU compared to control after 3, 7, 14, and 21 days, but a significant difference was not found. The AR-S assay, based on our experience, is rather suitable for quality than for quantity evaluation. Cells cultured on PUand PA-coated surface created hard and condensed calcium deposits, which were difficult to access and penetrate for AR-S to stain. Therefore, other methods to quantify the 
mineralized matrix deposition should be included in the study. Gene expression is one of the most reliable methods to identify and characterize activity during the whole osteoblast lineage. ${ }^{19}$ The selection of genes for monitoring should be well-defined based on the aims of the study. Therefore, we selected genes related to matrix formation (Collal), matrix maturation $(A l p l)$, and matrix mineralization (Bglap). ${ }^{29}$ Furthermore, we selected Runx2 expressed during the whole osteoblast lineage, from pluripotent stem cells to a stage of immature osteoblasts. Rankl produced by osteoblast in late stage of mineralization activating osteoclast was selected to investigate if the nanocoating is inhibiting the bone resorption by osteoclast. ${ }^{30,31}$ We found Runx2 to be upregulated after 3, 7, 14, and 21 days at the surface coated with both PU and PA, which leads to the conclusion that RG-Is influenced cell activity in the early stage itself, shortly after adhesion to the coated surface. This finding is important as Runx 2 is able to upregulate expression of genes involved in matrix formation, maturation, and mineralization, such as Collal, Alpl, osteopontin, bone sialoprotein, and Bglap. ${ }^{30}$ In our studies, expression of Colla1, Alpl, and Bglap have been increased at the surface coated with PU and PA compared to control after $3,7,14$, and 21 days. This is in agreement with results from a study by Gurzawska et al, ${ }^{25}$ which showed higher expression of Colla1, Alpl, and Bglap at the surface coated with RG-I from lupin unmodified, characterized with high content of galactose after 3 days. However, these genes have been measured only at one time point, while in this study four time points $(3,7,14$, and 21 days) were investigated, confirming that RG-Is coating activates osteoblast differentiation at different stages. This is the first study which analyzed the influence of RG-Is coating at different time points using two types of osteoblasts, MC3T3-E1 and primary osteoblast from mice. Our findings showed that PU and PA coating improved osteoblast proliferation, matrix formation, maturation, and mineralization, which may influence bone healing and osseointegration of the implants. In addition, our studies showed that the PU and PA coating downregulated Rankl compared to control at different time points, which is a crucial finding in relation to bone-resorbing osteoclasts. The Rankl expression results have revealed that RG-Is decreased receptor activator Rankl secretion in osteoblasts, suggesting a role in the osteoblast-induced inhibition of osteoclast differentiation. The inhibition of Rankl might prolong the osteoblast activity; however, it should be expressed to keep the bone remodeling in balance. ${ }^{32}$

The in vitro results revealed that RG-Is coating stimulated the osteoblast activity and suggested that the chemical structure of the molecule might modulate the cell response. Nanocoating with PA with a higher content of galactose influenced higher proliferation (BrdU), mineralized matrix formation (AR-S), and Runx2, Colla1, Alpl, and Bglap expression compared to PU nanocoating. ${ }^{24}$ It has previously been indicated that RG-I with high amounts of galactose enhanced cell spreading and growth, in contrast to the RG-I with high amounts of arabinan, which lead to aggregation and decreased proliferation. ${ }^{13-15,22,26}$ Our findings support our hypothesis that linear 1.4-linked galactans might be important for osteoblast differentiation, which has also been proposed in previous studies. ${ }^{24}$ Galectin-3 is present in the membrane of osteoblastic cells, which specifically binds to galactose residues, and it can therefore be speculated that the interaction with the RG-I galactans is mediated through galectin-3..$^{33,34}$ However, the hypothesis of linear 1.4-linked galactans influencing osteoblast behavior should be confirmed using other in vitro assays (protein expression) and microscopic investigations (immunofluorescence staining).

In summary, our in vitro results showed an increase in proliferation, mineralization, and gene expression in osteoblasts cultures on surfaces coated with RG-Is, particularly modified RG-I with high content of galactose.

\section{Conclusion}

The nanocoating with unmodified and enzymatically modified pectin RG-I from potato influenced osteoblast proliferation, mineralization, and gene expression. The results enriched the knowledge about RG-Is effect on osteoblast behavior at different time points. The structural properties of RG-Is have an influence on different cell responses, and further investigations about linear 1.4-linked galactans should be performed.

Our results showed that the RG-Is nanocoating might have the potential for further improvement of bone healing and osseointegration.

\section{Acknowledgments}

The project has been supported by Marie SkłodowskaCurie grant (FP-7 \# 290246). The authors thank RAPID (Rheumatoid Arthritis and Periodontal Inflammatory Disease) research group for providing support in performing experiments, and Bodil Jørgensen and Pete Ulvskov from University of Copenhagen for providing RG-Is.

\section{Disclosure}

The authors report no conflicts of interest in this work. 


\section{References}

1. Morra M. Biochemical modification of titanium surfaces: peptides and ECM proteins. Eur Cell Mater. 2006;12:1-15.

2. Albrektsson T, Wennerberg A. Oral implant surfaces: part 1 - review focusing on topographic and chemical properties of different surfaces and in vivo responses to them. Int J Prosthodont. 2004;17(5):536-543.

3. de Jonge LT, Leeuwenburgh SC, Wolke JG, Jansen JA. Organicinorganic surface modifications for titanium implant surfaces. Pharm Res. 2008;25(10):2357-2369.

4. Gurzawska K, Svava R, Jørgensen NR, Gotfredsen K. Nanocoating of titanium implant surfaces with organic molecules. Polysaccharides including glycosaminoglycans. J Biomed Nanotechnol. 2012;8(6): 1012-1024.

5. Le Guéhennec L, Soueidan A, Layrolle P, Amouriq Y. Surface treatments of titanium dental implants for rapid osseointegration. Dent Mater. 2007;23(7):844-854.

6. Meirelles L, Currie F, Jacobsson M, Albrektsson T, Wennerberg A. The effect of chemical and nanotopographical modifications on the early stages of osseointegration. Int J Oral Maxillofac Implants. 2008; 23(4):641-647.

7. Meirelles L, Melin L, Peltola T, et al. Effect of hydroxyapatite and titania nanostructures on early in vivo bone response. Clin Implant Dent Relat Res. 2008;10(4):245-254.

8. Mendonca G, Mendonca DB, Aragao FJ, Cooper LF. Advancing dental implant surface technology - from micron- to nanotopography. Biomaterials. 2008;29(28):3822-3835.

9. Wennerberg A, Albrektsson T. Effects of titanium surface topography on bone integration: a systematic review. Clin Oral Implants Res. 2009; 20(Suppl 4):172-184.

10. Wennerberg A, Albrektsson T. On implant surfaces: a review of current knowledge and opinions. Int J Oral Maxillofac Implants. 2010 25(1):63-74.

11. Wennerberg A, Albrektsson T, Andersson B. An animal study of c.p. titanium screws with different surface topographies. JMater Sci Mater Med. 1995;6(5):302-309.

12. Wennerberg A, Jimbo R, Stubinger S, Obrecht M, Dard M, Berner S. Nanostructures and hydrophilicity influence osseointegration: a biomechanical study in the rabbit tibia. Clin Oral Implants Res. 2013;25(9):1041-1050.

13. Bussy C, Verhoef R, Haeger A, et al. Modulating in vitro bone cell and macrophage behavior by immobilized enzymatically tailored pectins. J Biomed Mater Res A. 2008;86(3):597-606.

14. Kokkonen HE, Ilvesaro JM, Morra M, Schols HA, Tuukkanen J. Effect of modified pectin molecules on the growth of bone cells. Biomacromolecules. 2007;8(2):509-515.

15. Nagel MD, Verhoef R, Schols H, et al. Enzymatically-tailored pectins differentially influence the morphology, adhesion, cell cycle progression and survival of fibroblasts. Biochim Biophys Acta. 2008;1780(7-8):995-1003.

16. Brandley BK, Schnaar RL. Cell-surface carbohydrates in cell recognition and response. J Leukoc Biol. 1986;40(1):97-111.

17. Heinegård D. Connective tissue as the environment receiving tissue implants. In: Branemark P-I, Chien S, Gröndahl HG, Robinson K, editors. The Osseointegration Book. Berlin, Germany: Quintessence Publishing Co. Inc.; 2005:143-147.
18. Huh JE, Yang HR, Park DS, et al. Puerariae radix promotes differentiation and mineralization in human osteoblast-like SaOS-2 cells. J Ethnopharmacol. 2006;104(3):345-350.

19. Stein GS, Lian JB. Molecular mechanisms mediating proliferation/ differentiation interrelationships during progressive development of the osteoblast phenotype. Endocr Rev. 1993;14(4):424-442.

20. Franceschi RT. The developmental control of osteoblast-specific gene expression: role of specific transcription factors and the extracellular matrix environment. Crit Rev Oral Biol Med. 1999;10(1):40-57.

21. Krause C, de Gorter DJJ, Karperien M, Dijke P. Signal transduction casacades controlling osteoblasts differentiation. In: Clifford JR, editor. Primer on the Metabolic Bone Diseases and Disorders of Mineral Metabolism. Vol 7. Washinghton, DC: American Society of Bone and Mineral Research; 2008:10-16.

22. Morra M, Cassinelli C, Cascardo G, et al. Effects on interfacial properties and cell adhesion of surface modification by pectic hairy regions. Biomacromolecules. 2004;5(6):2094-2104.

23. Byg I, Diaz J, Øgendal LH, et al. Large-scale extraction of rhamnogalacturonan I from industrial potato waste. Food Chem. 2012; 131(4):1207-1216.

24. Gurzawska K, Svava R, Yihua Y, et al. Osteoblastic response to pectin nanocoating on titanium surfaces. Mater Sci Eng C Mater Biol Appl. 2014;43:117-125.

25. Gurzawska K, Svava R, Syberg S, et al. Effect of nanocoating with rhamnogalacturonan-I on surface properties and osteoblasts response. J Biomed Mater Res A. 2012;100(3):654-664.

26. Kokkonen H, Cassinelli C, Verhoef R, Morra M, Schols HA, Tuukkanen J. Differentiation of osteoblasts on pectin-coated titanium. Biomacromolecules. 2008;9(9):2369-2376.

27. Svava R, Gurzawska K, Yihau Y, et al. The structurally effect of surface coated rhamnogalacturonan I on response of the osteoblast-like cell line SaOS-2. J Biomed Mater Res A. 2014;102(6):1961-1971.

28. Byers BA, Pavlath GK, Murphy TJ, Karsenty G, Garcia AJ. Cell-typedependent up-regulation of in vitro mineralization after overexpression of the osteoblast-specific transcription factor Runx2/Cbfal. J Bone Miner Res. 2002;17(11):1931-1944.

29. Jonason JH, O'Keefe RJ. Isolation and culture of neonatal mouse calvarial osteoblasts. Methods Mol Biol. 2014;1130:295-305.

30. Neve A, Corrado A, Cantatore FP. Osteoblast physiology in normal and pathological conditions. Cell Tissue Res. 2011;343(2):289-302.

31. Gurzawska KA. Nanocoating of Implant Surfaces with Pectin Rhamnogalacturonan-ls, Review and In Vitro Studies [PhD thesis]. Copenhagen, Denmark: Faculty of Health and Medical Sciences, University of Copenhagen; 2013.

32. Rucci N. Molecular biology of bone remodelling. Clin Cases Miner Bone Metab. 2008;5(1):49-56.

33. Gao X, Zhi Y, Sun L, et al. The inhibitory effects of a rhamnogalacturonan I (RG-I) domain from ginseng pectin on galectin-3 and its structureactivity relationship. J Biol Chem. 2013;288(47):33953-33965.

34. Gunning AP, Bongaerts RJ, Morris VJ. Recognition of galactan components of pectin by galectin-3. FASEB J. 2009;23(2):415-424.
International Journal of Nanomedicine

\section{Publish your work in this journal}

The International Journal of Nanomedicine is an international, peerreviewed journal focusing on the application of nanotechnology in diagnostics, therapeutics, and drug delivery systems throughout the biomedical field. This journal is indexed on PubMed Central, MedLine, CAS, SciSearch ${ }^{\circledR}$, Current Contents ${ } /$ Clinical Medicine,

\section{Dovepress}

Journal Citation Reports/Science Edition, EMBase, Scopus and the Elsevier Bibliographic databases. The manuscript management system is completely online and includes a very quick and fair peer-review system, which is all easy to use. Visit http://www.dovepress.com/ testimonials.php to read real quotes from published authors. 